\title{
MODELLING AND MEASUREMENT OF BUBBLE FORMATION AND GROWTH IN ELECTROFLOTATION PROCESSES
}

\author{
Md. Shahjahan K. A. Sarkar ${ }^{1}$, Piotr M. Machniewski ${ }^{2}$, Geoffrey M. Evans ${ }^{1 *}$ \\ ${ }^{1}$ School of Engineering, The University of Newcastle, Callaghan, NSW, 2308 Australia \\ ${ }^{2}$ Warsaw University of Technology, Faculty of Chemical and Process Engineering, \\ ul. Waryńskiego 1, 00-645 Warsaw, Poland
}

\begin{abstract}
Electroflotation is used in the water treatment industry for the recovery of suspended particles. In this study the bubble formation and release of hydrogen bubbles generated electrolytically from a platinum cathode was investigated. Previously, it was found that both the growth rate and detachment diameter increased with increasing wire diameter. Conversely, current density had little effect on the released bubble size. It was also found that the detached bubbles rapidly increased in volume as they rose through the liquid as a result of decreasing hydrostatic pressure and high levels of dissolved hydrogen gas in the surrounding liquid. The experimental system was computationally modelled using a Lagrangian-Eulerian Discrete Particle approach. It was revealed that desorption of gaseous solutes from the electrolyte solution, other than hydrogen, may have a significant impact on the diameter variation of the formed bubbles. The simulation confirmed that liquid circulation, either forced or induced by the rising bubble plume, influences both the hydrogen supersaturation (concentration) in the neighbourhood of the electrode and the size of the resulting bubbles.
\end{abstract}

Keywords: electroflotation, bubble diameter, detachment, mass transfer, CFD modelling

\section{INTRODUCTION}

The recovery of fine particles is inversely related to bubble size and having bubble size smaller than that of conventional flotation device, and for these reasons electroflotation has the viability of being an efficient system for floating fine particles (Sarkar et al., 2010; Sarkar et al., 2011). Hence it is very important to have a clear understanding of the factors that influence the size of bubbles produced by electrolysis of water while designing an electroflotation system. The detachment of bubbles from electrodes and their subsequent growth while rising through the electrolyte solution containing dissolved gases is not well understood. There is a wide variation in reported measurements of bubble size across the literature. The uncertainty in influences of variables such as electrode curvature, surface preparation, and most importantly current density, on bubble size has made it difficult to effectively design efficient electroflotation systems for fine particle recovery. The fraction of hydrogen that results in gas bubbles is also an important factor in determining the bulk bubble diameter and flotation recovery. Recovery will be maximised if all of the electrolytically-produced gas results in the formation of gas bubbles. However, this may not always be the case since a portion of gases remains dissolved in solution (Müller et al., 1989; Sarkar et al., 2010; Vogt H., 1984a; Vogt H., 1984b).

For effective design of an efficient electroflotation system it is necessary to have a clear understanding of the influence of the bubble and particle sizes, buoyancy of bubble-particle aggregate, fractional

*Corresponding author, e-mail: Geoffrey.Evans@newcastle.edu.au 
coverage of bubble surface, contact angle of mineral-liquid-gas interface, current density, and solids concentration, etc., on recovery. While applying electroflotation commercially, the energy requirement for producing hydrogen and oxygen bubbles from electrolysis of water should also be considered. The aim of this study was to computationally model the formation, release and rise of hydrogen bubbles generated electrolytically by passing a known current through a platinum wire. In particular, the modelling included the dissolved hydrogen concentration profile in the surrounding fluid and its effect on the size of the hydrogen bubble as it rose through the liquid.

\section{EXPERIMENTAL}

The experimental system is that used by Sarkar et al. (2010a) and is shown in Fig.1. Briefly, the system consisted of a small vessel with dimensions 50 (W)x50(D)x15(H) mm. A $5 \mathrm{~mm}$ length of $190 \mu \mathrm{m}$ diameter platinum wire was placed in the horizontal position $10 \mathrm{~mm}$ from the base of the vessel and 5 $\mathrm{mm}$ from the front wall. A known electrical current was passed through the wire and at known time intervals the formation, rise and release of hydrogen bubbles from a nucleation site on the wire were recorded with a high speed video. Experiments were repeated for liquid vertically upward velocities of $0,2.5$ and $4.0 \mathrm{~mm} / \mathrm{s}$. The experimental apparatus and procedures are reported in detail in Sarkar (2011b).

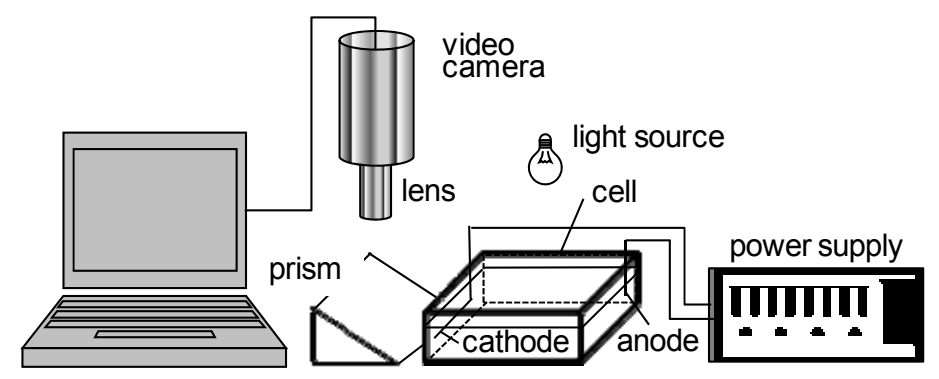

Fig. 1. Experimental apparatus (Sarkar et al., 2010)

\section{MODELLING}

In order to quantitatively explain observed diameter variation (growth) of the bubbles during their ascent after detachment from the electrode a numerical simulation of the process was undertaken in this study. For the simulation we have chosen the CFD approach, in which bubbles are treated as discrete particles tracked in a Lagrangian frame of reference and the continuous phase (liquid) is treated as a continuum in Eulerian perspective. The Lagrangian-Eulerian approach was successfully applied for modeling flow in bubble columns (Delnoij et al., 1997). A number of simplifying assumptions often have to be made, such as neglecting the finite size of particles and their influence on each other at higher volume fractions. In the system considered in this work the volume fraction of the dispersed phase is very low, which justifies such an approach. Based on the experimental observations, laminar flow of the liquid phase and spherical bubbles (20-50 micron in diameter) rising in a creeping flow regime were assumed in the simulation. The velocity field of the liquid (continuous) phase treated as divergence free (incompressible), was obtained by solving the momentum balance Eq. (1):

$$
\frac{\partial}{\partial t}(\rho \vec{u})+\nabla \cdot(\rho \vec{u} \vec{u})=-\nabla p+\nabla \cdot\left[\mu\left(\nabla \vec{u}+\nabla \vec{u}^{T}\right)\right]+\rho \vec{g}+\vec{f}
$$


Trajectories of the bubbles were calculated in the Lagrangian reference frame by integrating the equation of motion for an individual bubble:

$$
\rho_{B} V_{B} \frac{d u_{B}}{d t}=F_{D}+F_{V M}+F_{G}
$$

The terms on the right hand side correspond to forces acting on a bubble include the drag force, virtual mass inertia, and gravity, where:

$$
\begin{gathered}
F_{D}=\pi r_{B}^{2} C_{D} \rho\left|u_{B}-u\right|\left(u-u_{B}\right) / 2 \\
F_{V M}=\frac{1}{2} V_{B} \rho \frac{d}{d t}\left(u-u_{B}\right) \\
F_{G}=V_{B} g\left(\rho_{B}-\rho\right)
\end{gathered}
$$

Saffman lift force and the force due to pressure gradients (other than hydrostatic) were neglected. The source term, $f$, in Eq. (1) is responsible for bubble-liquid momentum exchange:

$$
f=\sum_{i} n_{B i}\left(F_{D}+F_{V M}\right)_{i} / V_{C E L L}
$$

where $n_{B i}$ is the number of bubbles of size $i$ present in each computational cell of volume $V_{\text {cell }}$ in the discretised domain. The drag coefficient in Eq. (3) can be calculated based on the HadamardRybczynski solution of creeping flow around a spherical gas bubble with either a fully mobile or immobile interface:

- mobile interface:

$$
C_{D}=16 / \mathrm{Re}
$$

- immobile interface (solid sphere):

$$
C_{D}=24 / \mathrm{Re}
$$

Bubble volume was observed to increase during its ascent. After detachment from the electrode mass transfer of the gaseous solutes from the surrounding liquid phase is mainly responsible for further variation (growth) of the rising bubble's diameter, as variation of the hydrostatic pressure is too small to explain the changes. Bubble volume can be expressed using ideal gas equation of state. The number of moles of component $i$ contained in a gas bubble varies with time according to the following equation:

$$
\frac{d n_{i}}{d t}=-k_{L i} \cdot \pi d_{B}^{2}\left(\frac{n_{i}}{V_{B}} \frac{1}{H e_{i}}-c_{L b, i}\right) \quad i=\left\{H_{2}, \mathrm{~N}_{2}, \mathrm{O}_{2}\right\}
$$

where volume, spherical bubble diameter and pressure are correspondingly given as:

$$
\begin{gathered}
V_{B}=\left(n_{\mathrm{H}_{2}}+n_{\mathrm{N}_{2}}+n_{\mathrm{O}_{2}}\right) R T / p \\
d_{B}=\sqrt[3]{6 V_{B} / \pi} \\
p=p_{0}+\rho g h+4 \sigma / d_{B}
\end{gathered}
$$

At the considered rate of bubble size variation and neglecting mass transfer resistance on the gas side, the value of the overall mass transfer coefficient $k_{L}$ in Eq. (9) can be estimated from the theoretically derived correlations for mass transfer coefficient outside a spherical particle. For the case of a mobile interface and creeping flow where $\mathrm{Re} \rightarrow 0$, Bird et al. (2002) suggested modification of the original expression by Levich (1962) in the form:

$$
S h=2+0.6415 R e^{0.5} S c^{0.5}
$$

Due to absorption of surface active impurities mobility of the interface in small bubbles is often 
retarded. In the case of an immobile interface an analogous expression assuming creeping flow was derived for solid spheres (Bird et al., 2002) is:

$$
S h=2+0.991 R e^{0.33} S c^{0.33}
$$

The bulk liquid concentration $c_{L b i}$ in Eq. (9) was obtained from the species conservation equation in the liquid phase (Eq. 15), which includes a source term due to mass transfer between the bubbles and the liquid $m_{i G L}$ calculated from the difference in mass of particles (bubbles) entering and leaving given computational cell.

$$
\frac{\partial \rho X_{i, L}}{\partial t}+\nabla \cdot\left(\rho \vec{u} X_{i, L}-\rho D_{i, L} \nabla X_{i, L}\right)=m_{i G L}
$$

The species conservation equation (15) was solved together with the momentum balance (Eq.1). The simulation was carried out with ANSYS-FLUENT software extended with momentum and mass exchange terms (Eqs. 7-13) coded in the form of user defined functions.

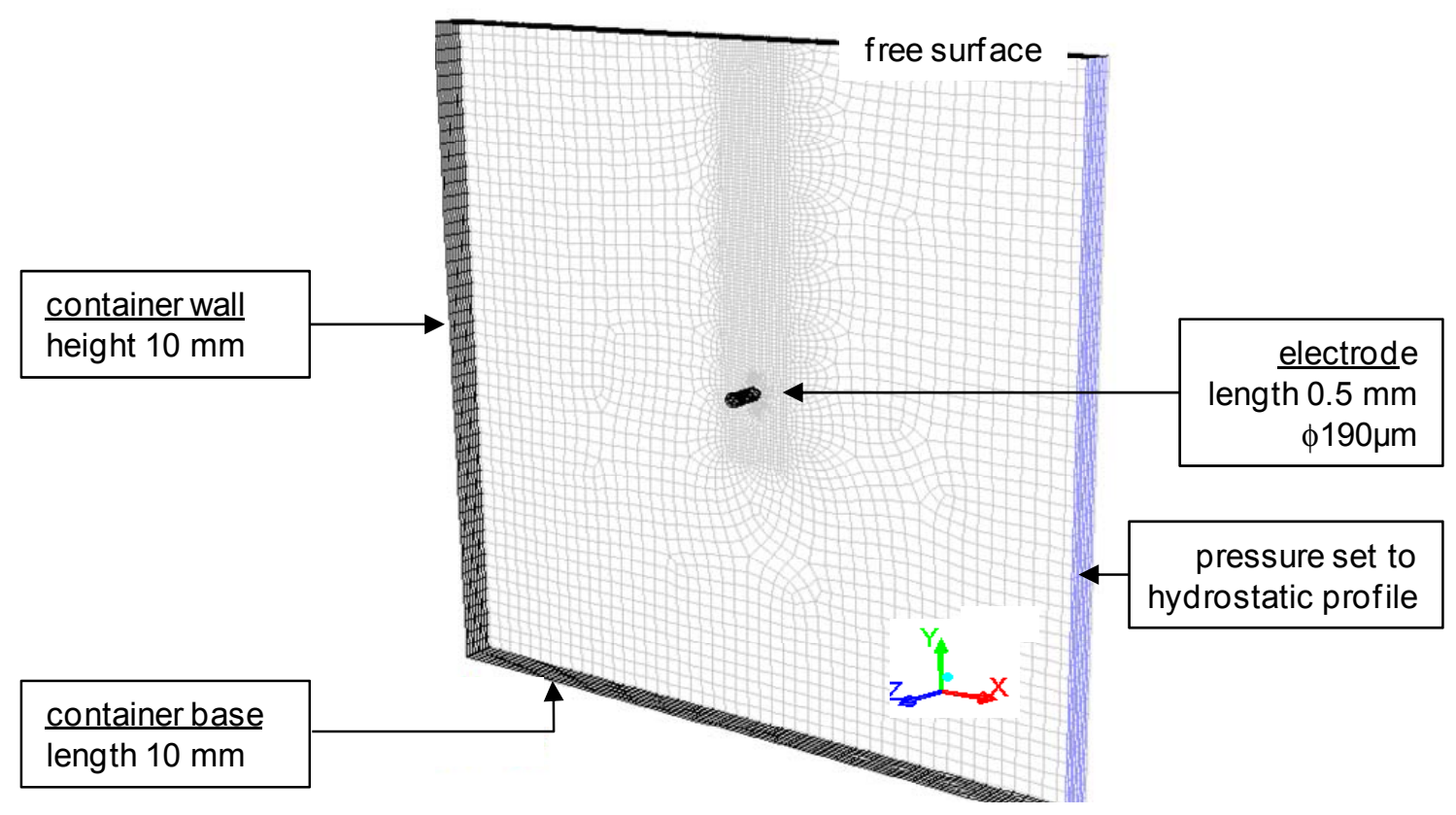

Fig. 2. Geometry and computational mesh

The geometry of the computational domain (Fig.2.) corresponded to a $0.5 \mathrm{~mm}$ section of the wire (190 $\mu \mathrm{m}$ in diameter) mounted $5 \mathrm{~mm}$ apart from the wall of container filled with liquid phase to the level of $(10 \mathrm{~mm})$. This section included one nucleation site corresponding to 10 nucleation sites per 5 $\mathrm{mm}$ on average. Symmetry was assumed on both sides of the section. In the lateral directions the boundary conditions correspond to zero velocity components and mass fluxes on bottom and side wall. The liquid free surface was modeled as a zero shear stress wall where saturation was assumed for air components and concentration of hydrogen was set to zero. Hydrostatic pressure was set as the boundary condition opposite to the container wall in order to enable liquid circulation from the bulk of the container. The inflowing liquid was assumed to be saturated with air and contained no dissolved hydrogen. Mass flux of dissolved hydrogen resulting from electrolysis was set as the boundary condition on the wire surface. The flux was calculated as equivalent to current density (i.e. $152 \mathrm{~A} / \mathrm{m}^{2}$ for a given set of experimental conditions) minus flux of gaseous hydrogen evolving in the form of detaching bubbles. The bubble detachment frequency was set to 11 bubble/s (based on experimental observations). The initial diameter of the bubbles (just after detachment) can be estimated by 
simultaneously solving Eqs. (16-17), which were obtained from a force balance between surface tension and gravity acting on a spherical bubble detaching from a curved surface (Sarkar et al., 2010).

$$
\begin{gathered}
d_{B, d}=\sqrt{\frac{24 \sigma}{g\left(\rho_{L}-\rho_{G}\right)}\left(\frac{\sin ^{2} \theta}{2+3 \cos \theta-\cos ^{3} \theta}\right)} \\
\theta=\frac{\omega}{1+\sin ^{-1}\left(d_{B, d} / D\right)}
\end{gathered}
$$

Predictions based on Eqs. (16-17) and using a contact angle, $\omega$, of $0.18^{\circ}$ were consistent with the observed diameter of detached bubbles of approximately $22 \mu \mathrm{m}$ for $152 \mathrm{~A} / \mathrm{m}^{2}$ current density and with no liquid upflow. In the case where liquid upflow was applied the boundary condition on the bottom was changed to specify an upflow liquid velocity of either 2.5 or $4 \mathrm{~mm} / \mathrm{s}$. The liquid was initially assumed to be at rest, saturated with air and contained no dissolved hydrogen. The computational mesh comprised of over 50000 quadrilateral elements in total. The grid size was refined down to $0.05 \times 0.05 \times 0.05 \mathrm{~mm}$ in the region around the electrode and bubble plume above the electrode, where the velocity and concentration gradients were the highest. In the remaining region of the domain flow was much calmer and the grid size of $0.05 \times 0.2 \times 0.2 \mathrm{~mm}$ assured mesh independent solution.

\section{RESULTS AND DISCUSSION}

From the transient simulations it was observed that a semi-steady state flow pattern was established after 15-20 s of flow time. The calculated velocity flow field and hydrogen concentration in the liquid phase on two perpendicular cross-sections, at time instant $30 \mathrm{~s}$ after starting the current when the semi steady state was established are shown in the Figs. 3 and 4, respectively.

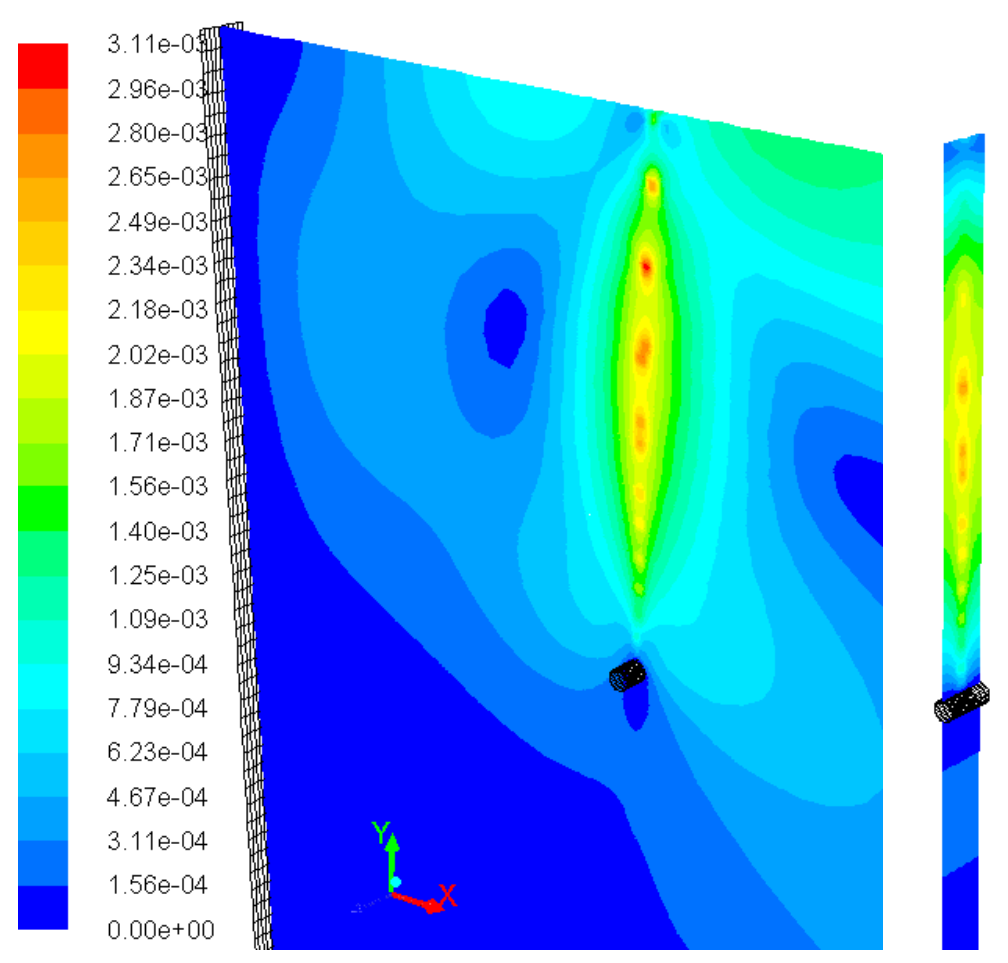

Fig. 3. Contours of liquid velocity magnitude (m/s) $30 \mathrm{~s}$ after current start-up. (3D simulation) 


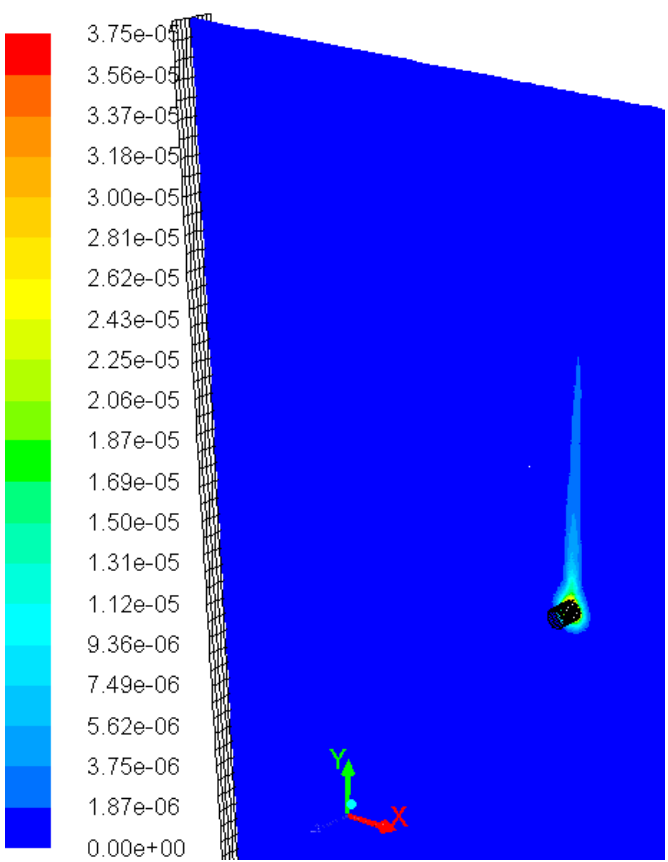

(a)

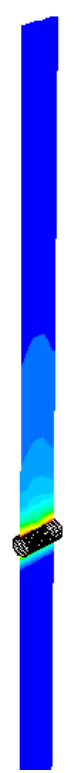

(b) (c)

Fig. 4. Hydrogen mass fraction contours at $30 \mathrm{~s}$ after current start-up in: (a) $\mathrm{x}-\mathrm{y}$, and

(b) z-y planes containing the electrode longitudinal (z) axis: (c) shows bubble diameter (scale: 20 (blue) 60 (red) $\mu \mathrm{m})$ as a function of vertical position (y)

It can be observed that the dissolved hydrogen concentration field around the electrode wire was strongly asymmetric, which was the result of convection induced by the rising plume of bubbles and simultaneous mass transfer. Thus the hydrogen supersaturation extends far from electrode surface causing constant growth of the ascending bubbles. At the beginning of the process, shortly after electric current startup, the hydrogen is transported only a short distance from the electrode by diffusion and the detached bubbles quickly collapse and disappear. This phenomenon was also observed in the experiments.

Evolution of hydrogen concentration profiles with time elapsed since current start-up, obtained from preliminary transient simulations based on assumption of semi-infinite tank (2D case), are shown in the Fig. 5. Variation of "solid" bubble diameters calculated for the same case is shown in the Fig. 6.

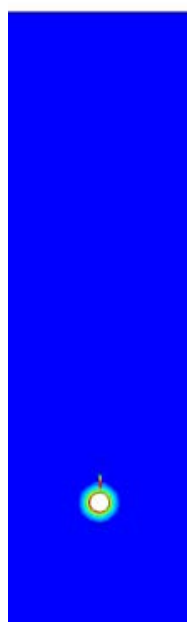

$\mathrm{t}=0.5 \mathrm{~s}$

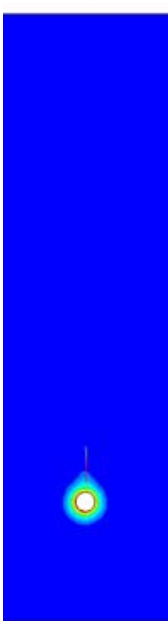

1s

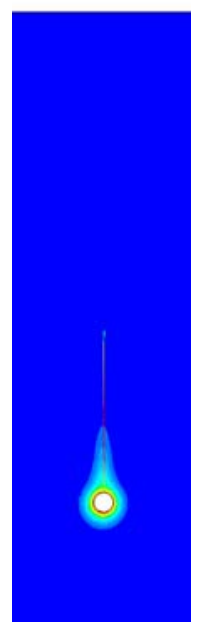

$2 s$

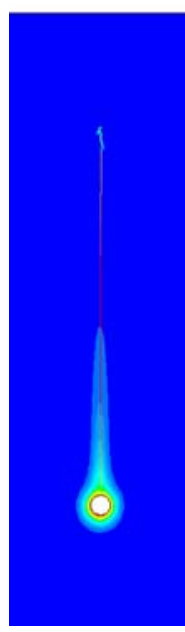

$3 \mathrm{~s}$

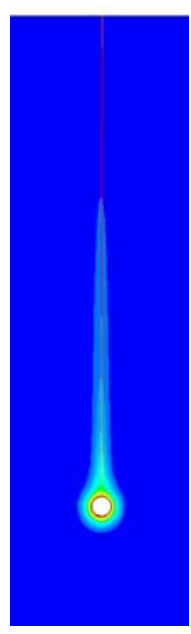

$4 \mathrm{~s}$

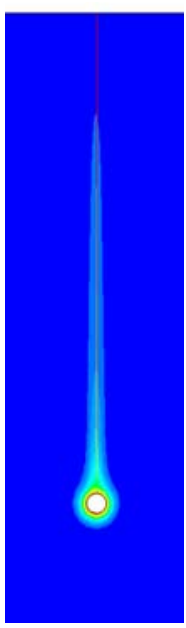

$5 s$

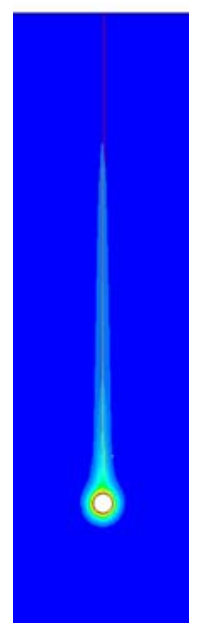

$10 \mathrm{~s}$

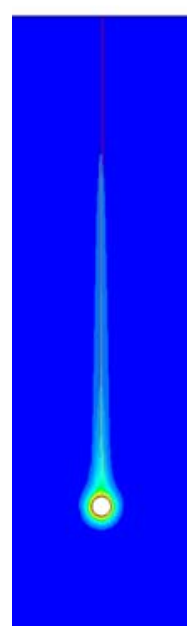

$15 \mathrm{~s}$

Fig. 5. Hydrogen concentration field in the liquid phase at different times elapsed after current start-up (2D simulation, semi-infinite tank) 


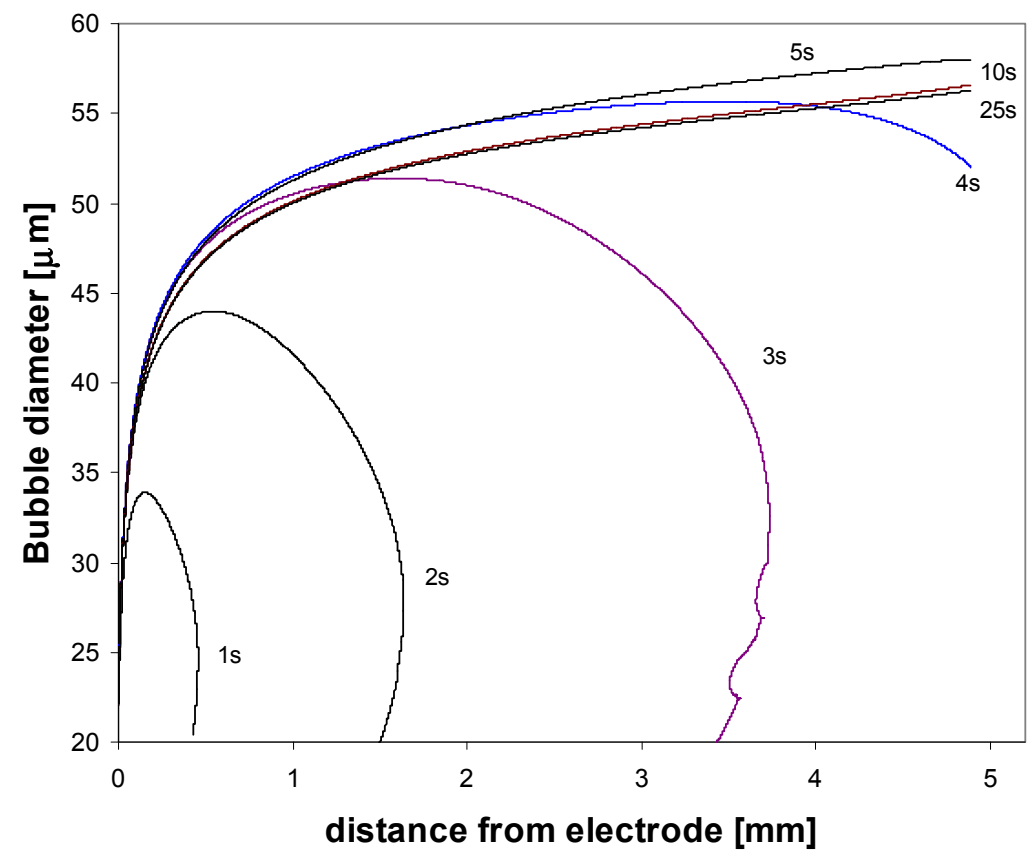

Fig. 6. Evolution of bubble diameters along their track at different times elapsed after current start-up ("immobile surface" bubbles, 2D simulation)

Comparison of measured and calculated bubble diameters at various locations above the detachment point is shown in Fig. 7. The diameter predictions based on both mobile and immobile interface mobility assumptions (Eqs. 13-14) are very close to each other. As the Reynolds numbers for the bubbles are very small (order of $10^{-2}$ ) both equations result in similar Sherwood number values (around 3 for $30 \mu \mathrm{m}$ bubbles).

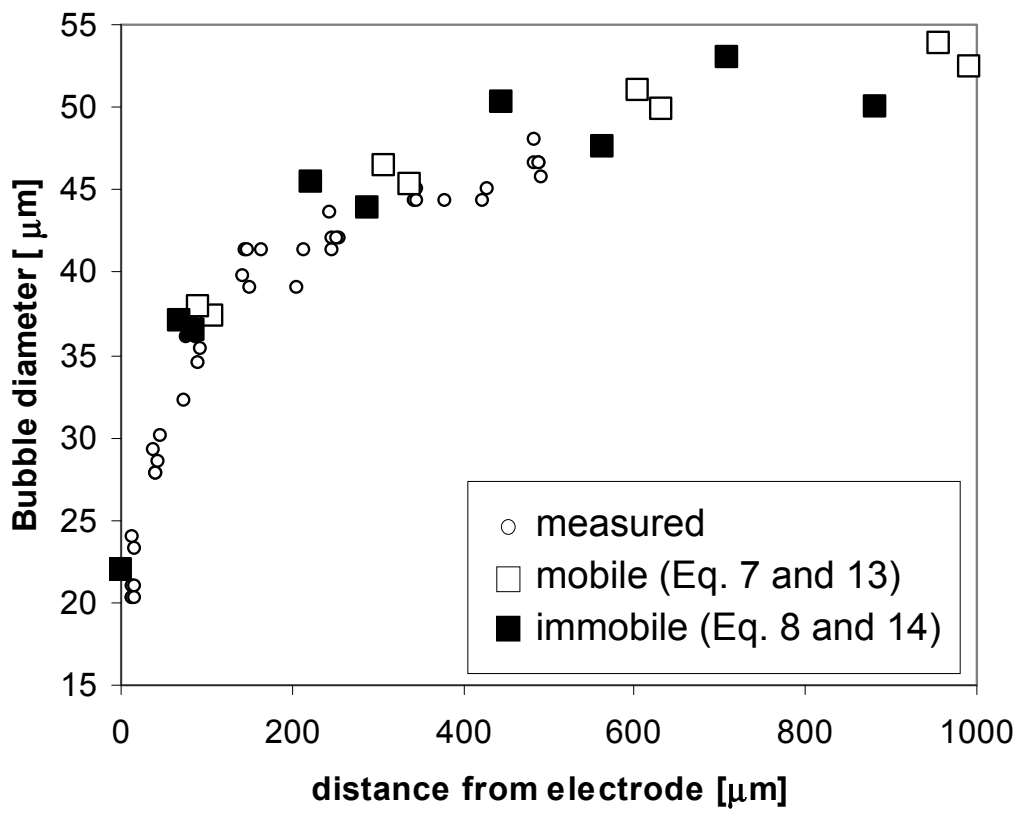

Fig. 7. Calculated and measured bubble diameter $\left(D=190 \mu \mathrm{m}\right.$, current density $\left.152 \mathrm{~A} / \mathrm{m}^{2}\right)$

It can be observed in Figs. 7 and 8 that both predictions fit the experimental data quite well; with bubble velocities calculated assuming an immobile interface are in better agreement with the measured velocities for bubble diameters smaller than $40 \mathrm{~mm}$, whereas measured velocities of bigger bubbles 
tend to be a bit higher and seem to align better with the values calculated based on the assumption of a mobile interface (Fig.8).

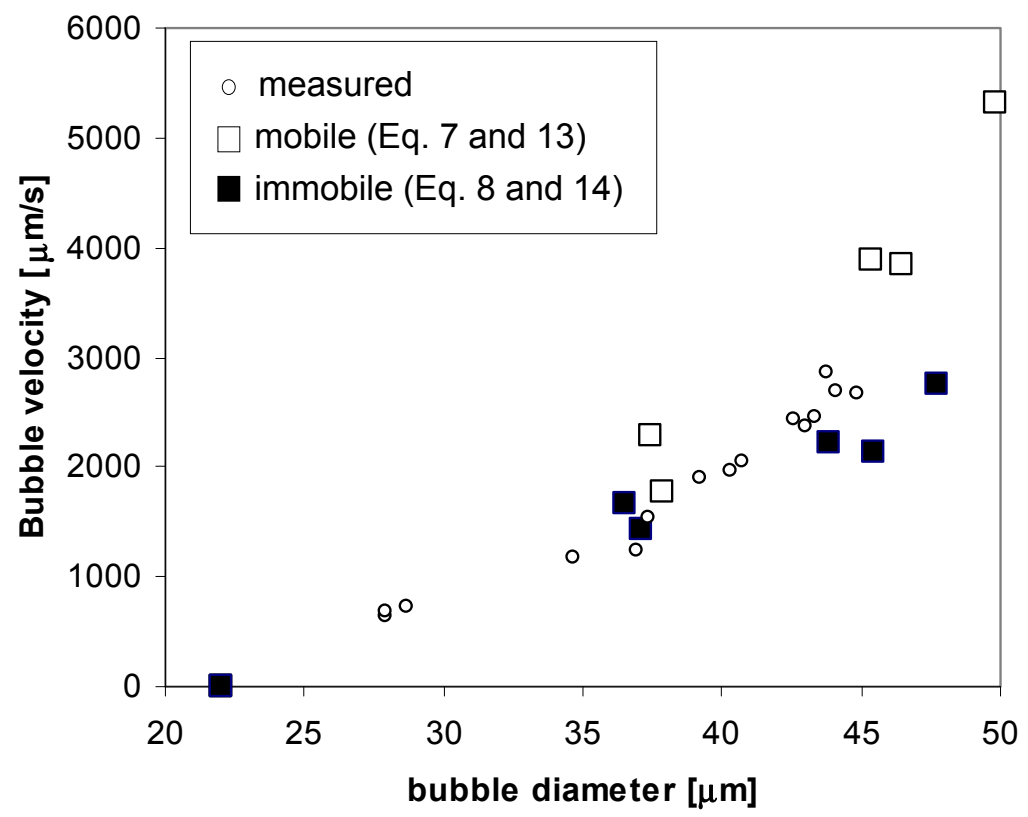

Fig. 8. Calculated and measured velocity of bubbles $\left(D=190 \mu \mathrm{m}\right.$, current density $\left.152 \mathrm{~A} / \mathrm{m}^{2}\right)$

Effect of liquid upflow is shown in Fig. 9. Smaller bubble diameters calculated for higher liquid upflow velocities are in fair agreement the measured bulk bubble diameters of 41.5 and $39.5 \mu \mathrm{m}$ at upflow liquid velocities of 2.5 and $4 \mathrm{~mm} / \mathrm{s}$, respectively.

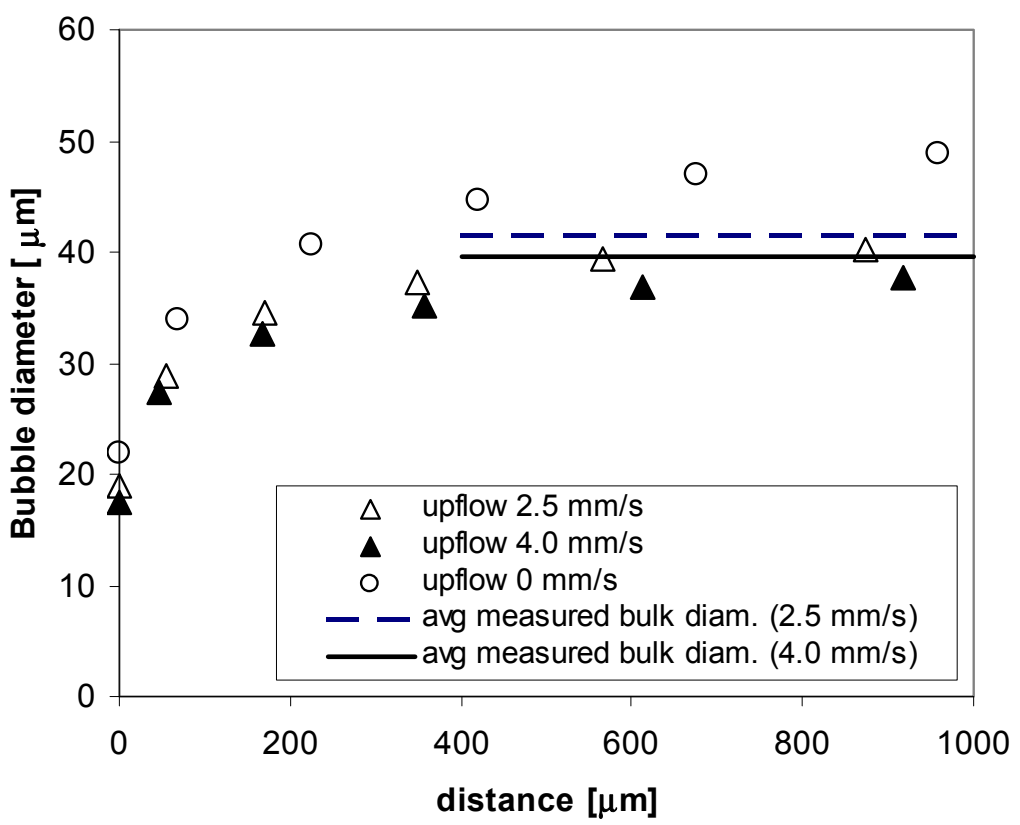

Fig. 9. Effect of liquid upflow on bubble diameter

The calculated bubble gas composition profile (Fig. 10) indicates possible dilution of the gaseous hydrogen as a result of desorption of the dissolved air components (nitrogen, oxygen) occurring in parallel to hydrogen mass transfer. 


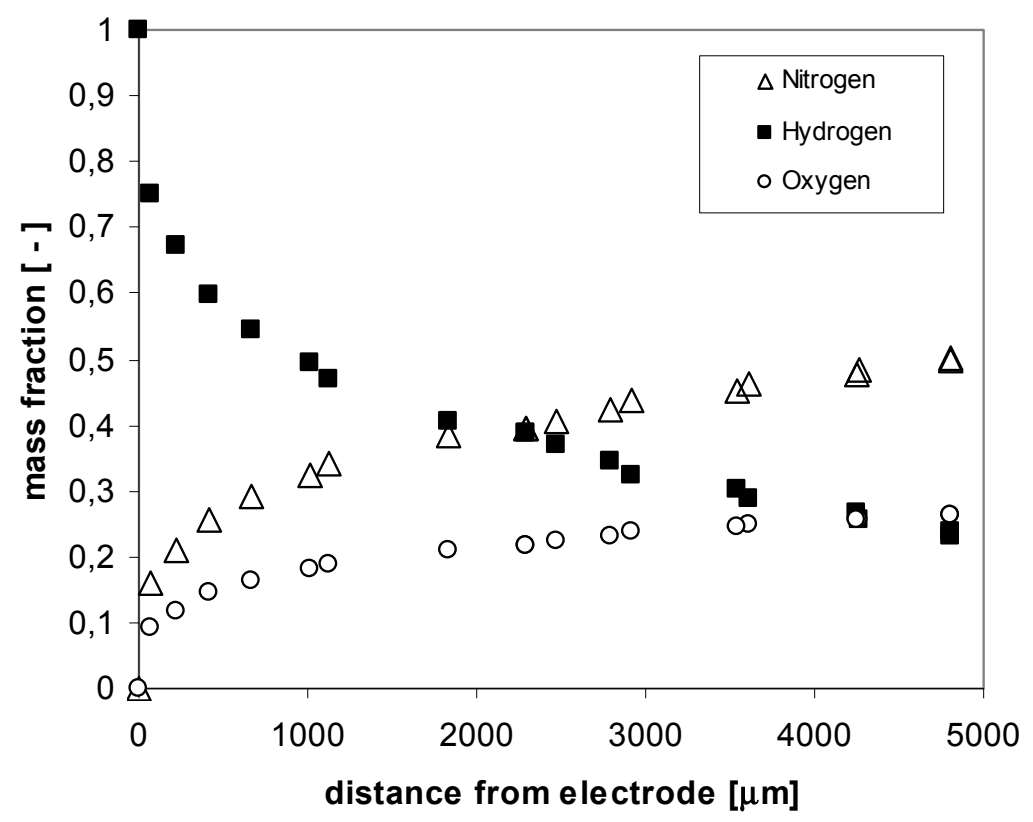

Fig. 10. Composition of gas in bubbles $\left(D=190 \mu \mathrm{m}\right.$, current density $\left.152 \mathrm{~A} / \mathrm{m}^{2}\right)$

\section{CONCLUSIONS}

Observed growth of bubble diameters after detachment from the electrode can be attributed to desorption of dissolved hydrogen and other gases (eg. nitrogen) from the liquid phase. The numerical simulations of the bubble plume confirms that an non-symmetric hydrogen supersaturation region extends far above the electrode. The Lagrangian-Eulerian Discrete Particle CFD model can be efficiently used to simulate hydrodynamics, mass transfer and bubble size variations in an electroflotation cell at low dispersed phase volume fractions. Despite many simplifying assumptions and lack of fitted parameters the agreement of the model predictions with experimentally determined bubble diameters and their velocities is quite good. The predicted effect of liquid upflow, which results in smaller bubbles due to dilution of hydrogen and the shorter residence time of bubbles in the supersaturation region, is also in reasonable agreement with experimental observations.

\section{SYMBOLS}

$c_{L b i} \quad$ molar concentration of species $i$ in liquid bulk, $\mathrm{mol} / \mathrm{m}^{3}$

$d_{B} \quad$ spherical bubble diameter, $\mathrm{m}$

$D \quad$ electrode diameter, $\mathrm{m}$

$D_{L} \quad$ molecular diffusion coefficient of species $i$ in the liquid phase, $\mathrm{m}^{2} / \mathrm{s}$

$f \quad$ source term due to momentum transfer, $\mathrm{N} / \mathrm{m}^{3}$

g gravitational acceleration, $\mathrm{m} / \mathrm{s}^{2}$

$F_{D} \quad$ drag force, $\mathrm{N}$

$F_{V M} \quad$ virtual mass force, $\mathrm{N}$

$F_{G} \quad$ gravity force, $\mathrm{N}$

$h \quad$ height of liquid layer above a bubble, $\mathrm{m}$

$\mathrm{He}_{i} \quad$ dimensionless Henry constant (gas-liquid partition coefficient for species $i$ )

$k_{L} \quad$ mass transfer coefficient, $\mathrm{m} / \mathrm{s}$

$m_{i G L} \quad$ source term due to mass transfer of component $i, \mathrm{~kg} / \mathrm{m}^{3} \mathrm{~s}$ 


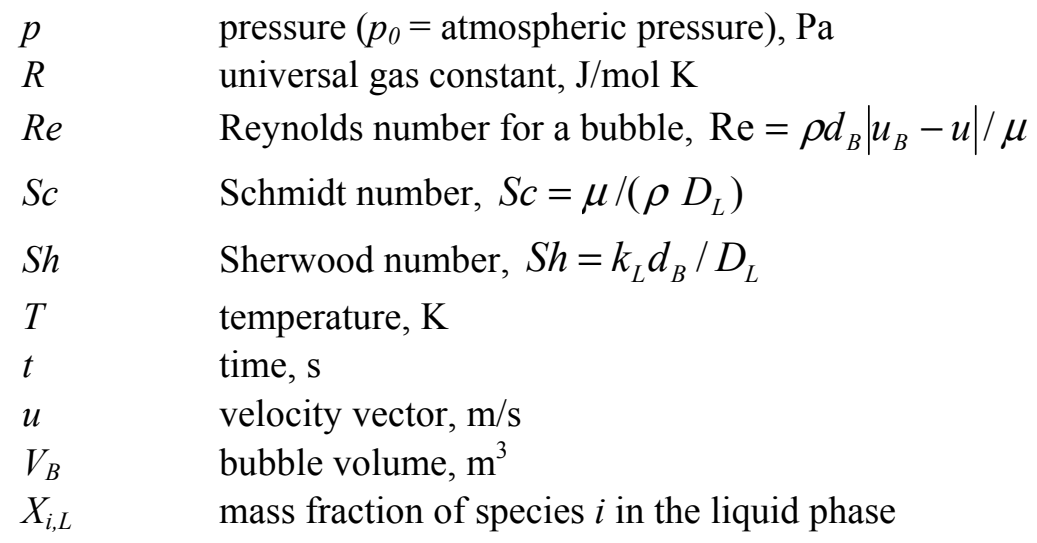

Greek symbols

$\begin{array}{ll}\mu & \text { dynamic viscosity of the liquid phase, } \mathrm{Pa} \mathrm{s} \\ \rho & \text { density of the liquid phase, } \mathrm{kg} / \mathrm{m}^{3} \\ \sigma & \text { surface tension, } \mathrm{N} / \mathrm{m}\end{array}$

\section{REFERENCES}

Bird R.B., Steward W.E., Lightfoot E.N., 2002. Transport Phenomena. $2^{\text {nd }}$ ed., John Wiley \& Sons, New York.

Delnoij E., Lammers F.A., Kuipers J.A.M., van Swaaij W.P.M., 1997. Dynamic simulation of dispersed gasliquid two-phase flow using discrete bubble model. Chem. Eng. Sci., 52, 1429-1458. DOI: 10.1016/S00092509(96)00515-5.

Levich V., 1962. Physicochemical Hydrodynamics. Prentice-Hall, Englewood Cliffs, NY.

Müller L., Krenz M., Rübner K., 1989. On the relation between the transport of electrochemically evolved $\mathrm{Cl}_{2}$ and $\mathrm{H}_{2}$ into the electrolyte bulk by convective diffusion and by gas bubbles. Electrochimica Acta, 34, 305-308. DOI: 10.1016/0013-4686(89)87002-1.

Sarkar M.S.K.A., Donne S.W., Evans G.M., 2010. Hydrogen bubble flotation of silica. Adv. Powder Technol., 21, 412-418. DOI: 10.1016/j.apt.2010.04.005.

Sarkar M.S.K.A., Evans G.M., Donne S.W., 2010. Bubble size measurement in electroflotation. Minerals Engng., 23, 1058-1065. DOI: 10.1016/j.mineng.2010.08.015.

Sarkar M.S.K.A., Donne S.W., Evans G. M., 2011. Utilization of hydrogen in electroflotation of silica. Adv. Powder Technol., 22, 482-492. DOI: 10.1016/j.apt.2011.05.007.

Sarkar M.S.K.A., 2011. Electroflotation: Its application to water treatment and mineral processing. PhD Thesis, The University of Newcastle, Australia.

Vogt H., 1984a. The rate of gas evolution of electrodes-i. An estimate of the efficiency of gas evolution from the supersaturation of electrolyte adjacent to a gas-evolving electrode. Electrochimica Acta, 29, 167-173. DOI: 10.1016/0013-4686(84)87043-7.

Vogt H., 1984b. The rate of gas evolution at electrodes-ii. An estimate of the efficiency of gas evolution on the basis of bubble growth data. Electrochimica Acta, 29, 175-180. DOI: 10.1016/0013-4686(84)87044-9.

Received 04 January 2013

Received in revised form 27 May 2013

Accepted 16 June 2013 